\title{
Complex hybridity in Isotoma petraea. VI. Distorted segregation, gametic lethal systems and population divergence
}

\author{
P. Lavery and S. H. James
}

\author{
Botany Department, University of Western Australia, \\ Nedlands, Western Australia. 6009.
}

Unequal recovery of complexes in crosses involving Isotoma petraea complex heterozygotes may be due to (a) the components of the zygotic lethal system in one complex being distributed over both complexes in a second complex hybrid, (b) to the dependence of a complex containing a dominant lethal factor on a suppressor of that lethal in the other complex for its survival, and (c) to gametic lethals. The redistribution of zygotic lethal system components between complexes in different complex heterozygotes leads to a limitation of the number of complex combinations possible in interpopulational hybrids and to the development of partial genetic isolation between populations.

Unbalanced gametic lethals, operating in either the pollen or ovule, are not uncommon in Isotoma complex hybrids, and one plant stabilised by a balanced gametic lethal system is described. It is concluded that balanced gametic lethal systems in Isotoma could eventually replace the more primitive zygotic lethal systems, and that a similar evolutionary sequence probably accounts for the preponderance of gametic lethal systems in Oenothera complex hybrids.

\section{INTRODUCTION}

Complex hybridity is a rare genetic system which associates multiple interchange hybridity, autogamy and a balanced lethal system to conserve permanent hybridity at the diploid level. It is found in Isotoma petraea (James, 1965), Oenothera spp. (Cleland, 1960, 1972), Rhoeo discolor (Simmonds, 1945), Hypericum (Hoar, 1931) and Gayophytum (Thein, 1969). Genetic systems approaching complex hybridity are also known in a number of dioecious groups, including Viscum (Weins and Barlow, 1975), termites (Syren and Luykx, 1977, 1981), centipedes (Ogawa, 1954), huntsman spiders (Rowell, 1985) and monotremes (Murtagh, 1977). Within complex hybrid species, essentially only two gametic genotypes, the complexes, are formed, and on selfing, the complex combinations which survive are determined by the balanced lethal system.

The balanced lethal systems in autogamic complex hybrid plant species are of two forms, zygotic and gametic. In the zygotic system, the complex homozygotes are formed as zygotes but fail to survive due to the operation of recessive lethal genes. In the gametic system, complex homozygotes are not formed because of the complementary transmission of the complexes in alternate sexes. Steiner $(1956,1957,1960)$ has attributed the widespread occurrence of gametic lethal systems in Oenothera, in part, to self-incompatibility factors, presumably relics from an ancestral outbreeding form, which have been maintained in the female transmissible complex. The Renner Effect, which is megaspore competition favouring the survival of one genotype, harbours the female component of the balanced gametic lethal system in Oenothera complex hybrids, ensuring that the alternate complex is transmitted through the ovule.

James (1965), Beltran and James (1970) and Beltran (1971) have shown that complex hybridity is maintained in some forms of Isotoma petraea through balanced zygotic lethal systems which allow equal transmission of both complexes in the gametes. No evidence of self-incompatibility has been reported in I.petraea, and indeed most of the seed produced by both the structurally homozygous ancestral forms and the complex hybrids is by self-pollination.

More recently, however, it was observed that an apparently unequal transmission of complexes occured when certain complex hybrids were crossed to alethal structural homozygotes. A fully or partially developed gametic lethal system is one of several ways of explaining this observation, and the apparent operation of synthetic gametic lethals 
in maintaining independently assorting rings in two-ring complex heterozygotes (James 1970), as well as the presence of gametic lethals in comparable genetic systems in other species, strengthens this possible option.

This paper describes the transmissibility of complexes in several Isotoma petraea complex heterozygotes in self and cross pollinations and confirms the occurrence of distorted segregations in several cases. Three different mechanisms resulting in segregation distortion are described. Two of these mechanisms are dependent upon the interactions of components of the zygotic lethal systems when combined in interpopulational hybrids, and they exemplify situations in which the often nebulous concepts of intrapopulational coadaptation and interpopulational divergence are more precisely defined. The third mechanism described is one based on gametic lethality. The significance of the occurrence of gametic lethal systems in relation to proposed evolutionary pathways to complex hybridity is discussed.

\section{MATERIALS AND METHODS}

A series of crosses involving complex heterozygotes and alethal structural homozygotes was established in the glasshouse. The locations of the source populations are available in James (1970). Naturally self-pollinated capsules were also harvested. About 7 days after harvesting, the seeds were leached in a running waterbath for 72 hours then imbibed in 0.1 per cent giberellic acid (GA3$\mathrm{BDH}$ Chemicals) for 48 hours to break the natural dormancy of the seed. They were then germinated on clean wet Whatman's No. 1 filter papers in sterile petri dishes. Samples of 2- to 3-week-old seedlings were transferred individually to $5 \times 5 \mathrm{~cm}$ Jiffy peat pots and scored for seedling survival rates.

Electrophoresis was conducted on samples of 2- to 3-weak-old seedlings (LAP assay only) and on plants which survived to maturity in Jiffy pots (usually PGM, GDH, LAP, GOT and 6-PGD assays). Details of the electrophoretic techniques are available in James et al. (1983).

Pollen from selected plants was collected and stored at room temperature in dry microtiter wells covered with plastic film. Each day for 5 days a sub-sample was removed and assayed electrophoretically for all five loci.

Growth patterns of pollen from complex hybrids were monitored in the style of a standard structural homozygote (Gnarlbine 9). Mature stigmas of emasculated flower buds were dusted with pollen and at intervals of up to 24 hours the styles were removed and the conducting tissue dissected out and stained with 1 per cent aniline blue in 5 per cent glycerol. The tissue was then squashed and observed under UV for pollen tube fluorescence using a Carl Zeiss (Jena) Fluoval microscope with barrier filter GA-24 and excitation filter UG-1.

Pollen viability was determined by staining in 5 per cent lactophenol cotton blue in 45 per cent acetic acid or with fluorescein diacetate (Knox 1979) and by scoring the percentage of germinated grains after 24 hours in a 10 per cent sucrose "hanging drop" cell.

Embryological features of particular plants were studied by embedding a range of ovaries fixed in 6 per cent gluteraldehyde in GMA resin (O'Brien and McCully, 1982). Sections were cut at $2.5 \mu \mathrm{m}$ using a Sorvall JB-4 microtome, mounted in sequence on a glass slide and stained in toluidine blue ( $p \mathrm{H} \mathrm{6.8)}$.

Ovule numbers were determined by staining placentae with attached ovules in alcoholic carmine (Snow, 1963) at $60^{\circ} \mathrm{C}$ for one hour and dissecting the ovules onto a gridded filter paper for counting. Excess stain was removed with 45 per cent acetic acid.

The contents of mature unopened capsules from selected plants were determined by dissection.

The meiotic configuration at first metaphase was determined for occasional plants using the alcoholic carmine squash technique (Snow, 1963).

In the following, italicisation of locality in individual plant names indicates that the plant is a complex hybrid.

\section{OBSERVATIONS}

\section{Zygotic elimination of one complex in Elachbutting 5}

Elachbutting 5 was determined as $1 / 31 / 21 / 31 / 2$ $1 / 1$ at the PGM, GDH, LAP, GOT- 1 and 6PGD-1 loci respectively. On selfing, it yielded $1 / 31 / 21 / 3$ $1 / 21 / 1$ heterozygous two-ring-of-six $\left(20_{6}\right)$ plants only, and exhibited a 90 per cent seedling survival rate (Table 1, cross 1 ). Gnarlbine 9 and Boorabbin 16 were $1 / 1$ 1/1 3/3 1/1 $1 / 1$ homozygotes. When crossed together, they yielded progeny homozygous both structurally $\left(7_{11}\right)$ and allozymically, with a seedling survival rate of 91 per cent (table 1, cross 2). When Elachbutting 5 was crossed to either standard alethal structural homozygote, the $1 / 11 / 13 / 31 / 1 \quad 1 / 1$ genotype was preferentially recovered in the adult progeny irrespective of the direction of the cross (table 1, crosses 3-6). Only 
Table 1 Progeny analyses

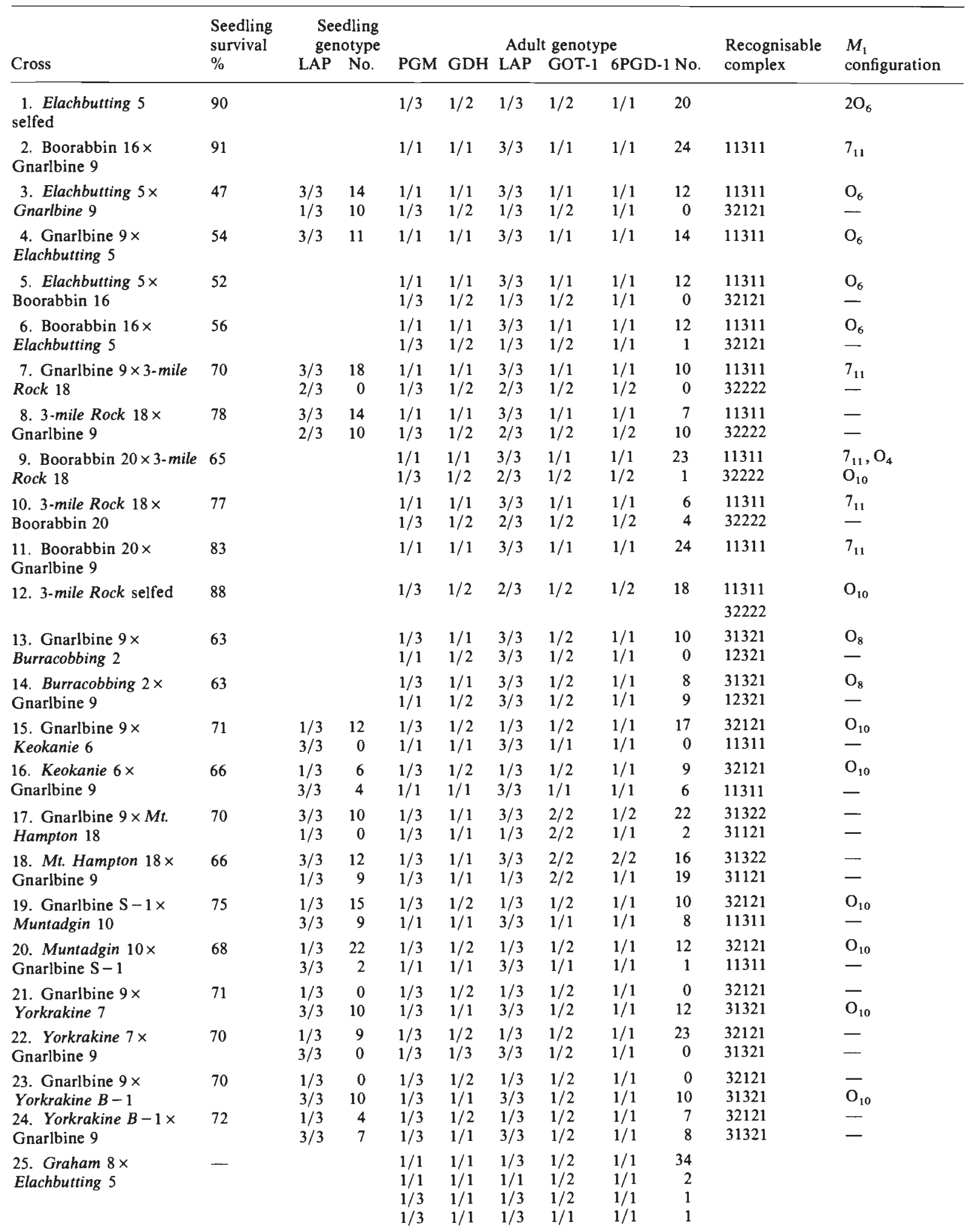


Table 1 (continued)

\begin{tabular}{|c|c|c|c|c|c|c|c|c|c|c|}
\hline \multirow[b]{2}{*}{ Cross } & \multirow[t]{2}{*}{$\begin{array}{l}\text { Seedling } \\
\text { survival } \\
\%\end{array}$} & $\begin{array}{l}\text { Seedling } \\
\text { genotype }\end{array}$ & \multirow[b]{2}{*}{ PGM } & \multicolumn{5}{|c|}{ Adult genotype } & \multirow{2}{*}{$\begin{array}{l}\text { Recognisable } \\
\text { complex }\end{array}$} & \multirow{2}{*}{$\begin{array}{l}M_{1} \\
\text { configuration }\end{array}$} \\
\hline & & LAP No. & & GDH & LAP & GOT-1 & 6PGD-1 & No. & & \\
\hline $\begin{array}{l}\text { 28. Gnarlbine } 2 \times M t \\
\text { Stevens } 3\end{array}$ & - & & $\begin{array}{l}1 / 3 \\
1 / 3\end{array}$ & $\begin{array}{l}1 / 1 \\
1 / 2\end{array}$ & $\begin{array}{l}3 / 3 \\
1 / 3\end{array}$ & $\begin{array}{l}* / 2 \\
* / 2\end{array}$ & $\begin{array}{l}1 / 1 \\
1 / 1\end{array}$ & $\begin{array}{r}15 \\
5\end{array}$ & $\begin{array}{l}31321 \\
32121\end{array}$ & \\
\hline $\begin{array}{l}\text { 29. Merredin } 9 \times M t \\
\text { Stevens } 3\end{array}$ & - & & $\begin{array}{l}3 / 3 \\
1 / 3 \\
1 / 3 \\
3 / 3\end{array}$ & $\begin{array}{l}2 / 2 \\
1 / 2 \\
1 / 1 \\
1 / 2\end{array}$ & $\begin{array}{l}1 / 1 \\
1 / 3 \\
3 / 3 \\
1 / 3\end{array}$ & $\begin{array}{l}2 / 2 \\
2 / 3 \\
2 / 3 \\
2 / 2\end{array}$ & $\begin{array}{l}1 / 1 \\
1 / 1 \\
1 / 1 \\
1 / 1\end{array}$ & $\begin{array}{r}45 \\
32 \\
8 \\
2\end{array}$ & & \\
\hline
\end{tabular}

* $=1$ or 2 , since the Gnarlbine 2 structural homozygote was genotypically $1 / 2$ at the GOT-1 locus.

two $1 / 31 / 21 / 31 / 21 / 1$ genotypes were observed amongst the 52 adult progeny examined. These results define the two Elachbutting 5 complexes as 11311 and 32121 with respect to the alleles they carry at the 5 loci assayed.

Seedling progeny from crosses 3 and 4 (table 1) included both LAP $1 / 3$ and $3 / 3$ genotypes, corresponding to the 32121 and 11311 genomes respectively, in frequencies not significantly different from a $1: 1$ ratio. These seedlings showed no signs of mortality after 3 weeks growth in petri dishes under non-selective conditions. However, in the materials transplanted into Jiffy pots to grow to maturity, approximately 50 per cent seedling mortality was observed, along with the preferential recovery of the 11311 genome. We conclude that the LAP $1 / 3$ seedlings, which carry the Elachbutting 532121 complex, are selectively eliminated during this phase.

The above results eliminate the possibility of a gametic lethal operating in Elachbutting 5. Both complexes are incorporated into and transmitted through both gametes in equal frequencies and are recoverable in young seedlings. A seedling lethal must therefore operate to eliminate the heterozygously marked twin hybrid, accounting for the 50 per cent seedling mortality which occurred after transplanting into Jiffy pots. This behaviour can be accommodated by assigning a dominant lethal factor to the 32121 complex and a suppressor of that lethal to the 11311 complex, in addition to the recessive lethal factors of the balanced lethal system which eliminate the complex homozygotes before seed maturation. As such, the selfed progeny which are complex heterozygous are viable. Both the Gnarlbine 9 and Boorabbin 16 primitive genomes, however, must lack the suppressor, for the lethal is expressed when in combination with these genomes.

Since no mortality was evident in the 3 -weekold seedlings, the dominant lethal of Elachbutting 532121 must exert its effect only after 3 weeks or under more stringent conditions. The two surviving adult heterozygotes noted in crosses 4 and 6 (table 1) may be recombinants in which the dominant lethal or its suppressor has been relocated relative to the allozyme markers.

\section{Unbalanced male gametic lethal systems in 3-Mile Rock 18 and three other complex heterozygotes}

A significant non-recovery of one complex in both the adult and, when tested, the seedling progeny was observed when 3-mile Rock 18, Burracobbing 2, Keokanie 6 and Mt. Hampton 18 were used as pollen donors in crosses to the alethal homozygote Gnarlbine 9 and when 3-mile Rock 18 was similarly crossed to Boorabbin 20. In the reciprocal crosses, both twin hybrids were recovered in frequencies not significantly different from a $1: 1$ ratio (table 1 , crosses 7-18).

The male recoverable complex in 3-mile Rock 18 was the 11311 complex. In combination with the similarly marked genomes from both of the alethal structural homozygotes, this complex yielded 29 structurally homozygous progeny exhibiting seven bivalents $\left(7_{11}\right)$ at meiosis and two ring-of-four $\left(\mathrm{O}_{4}\right)$ interchange heterozygotes amongst a total of 46 progeny grown to maturity. The $\left(7_{11}\right.$ Boorabbin $20 \times 7_{11}$ Gnarlbine 9) hybrid was structurally homozygous (table 1 , cross 11 ). Evidently, then, the 3-mile Rock male transmissible 
complex and both the Gnarlbine 9 and Boorabbin 20 genomes are identical for chromosome end sequences. The two $\mathrm{O}_{4}$ allozyme homozygote progeny observed in the Boorabbin $20 \times 3$-mile Rock 18 cross may be attributed to recombination in the complex hybrid parent.

Different allozymic markers were associated with the male recoverable complexes in other plants assayed (Burracobbing 2, 31321; Keokanie 6, 32121 and Mt. Hampton 18, 31322). The nonrecoverable complexes also exhibited considerable allozyme diversity, 32222, 12321, 11311 and 31121 in 3-mile Rock 18, Burracobbing 2, Keokanie 6 and Mt. Hampton 18 respectively.

Zymograms of 3-mile Rock 18 pollen exhibited an equal intensity for each band at the heterozygous loci, and both bands were detectable in the pollen after 5 days storage. It is therefore assumed that both types of pollen arrived at the stigma in any pollination event involving 3-mile Rock 18 as male. While the Gnarlbine 9 pollen exhibited about 95 per cent germination in 10 per cent sucrose after 24 hours, approximately 50 per cent of the apparently viable grains from all four complex hybrids failed to germinate. The pollen which did germinate did so after 45 to 60 minutes. It is not unreasonable to conclude that the pollen which failed to germinate was that which contained the non-recovered complexes. The pollen of 3-mile Rock 18 growing in the style of Gnarlbine 9 appeared to be homogenous with respect to its growth rates, and reached the placentae in less than 20 hours.

Examination of a mature 3-mile Rock 18 selfed capsule revealed that 232 mature seeds formed from 707 ovules. This level of seed production (32.8 per cent) is almost precisely half the pollen fertility. Since Beltran (1970) showed that in several Isotoma complex hybrids pollen and ovule fertility are equivalent, it can be concluded that half the fertile ovules in 3-mile Rock 18 set seed on selfing. The surviving seeds were all $\mathrm{O}_{10}$ complex heterozygote (table 1, cross 12), so the 11311 complex homozygote seeds must be removed by recessive lethality. Cursory examination of the capsules on the alethal Gnarlbine 9 and Boorabbin 20 derived by pollination from 3-mile Rock 18 showed that a large majority of the ovules developed into mature seeds, and all but one of the 52 progeny analysed were $1 / 1$ 1/ $13 / 31 / 11 / 1$ homozygotes. The one exception may well have been a recombinant. Were a balanced zygotic lethal system responsible for the permanent hybridity in 3-mile Rock 18 then both twin hybrids would have been expected in this progeny. The results observed, however, effectively eliminate the possibility that zygotic or seedling lethality was responsible for the observed segregation distortion, but they do support the contention that a form of gametic lethality effectively inhibits the transmission of the 32222 complex in the pollen of 3-mile Rock 18. Similar systems determine the nontransmissibility of one complex in the pollen of Burracobbin 2, Keokanie 6 and Mt. Hampton 18.

\section{An unbalanced female gametic lethal system in Muntadgin 10}

A biased recovery of the 32121 complex was evident in both the seedling and adult progeny of crosses where Muntadgin 10 was used maternally against the alethal structural homozygote Gnarlbine $S-1$, while in the reciprocal cross, both complexes were recovered in essentially equal frequencies (table 1, crosses 19 and 20). Elimination of the 11311 complex in the ovules via a female gametic lethal system, and undisturbed transmission of both complexes in the pollen would accommodate these observations. The three observed departures from female non-transmissibility may be attributed to recombination.

Another female gametic lethal system is described in the following section.

\section{A balanced gametic lethal system in Yorkrakine 7}

From table 1, crosses 21 and 22, it is evident that unequal but complementary recovery of complexes occurred in the pollen and ovules of Yorkrakine 7. This was evident in both seedling and adult progenies. The 31321 complex was transmitted in the pollen and the 32121 complex was transmitted through the ovules.

Biased complex recovery occurred in only the pollen of Yorkrakine B-1 (crosses 23 and 24) and in five other Yorkrakine plants (results not shown). Yorkrakine 7 and Yorkrakine B-1 have similar allozyme genotypes and cytology, both being $\mathrm{O}_{12}$, and when crossed paternally to alethal structural homozygotes, both gave rise to $\mathrm{O}_{10}$ progeny. Their male transmissible genomes are not identical, however, since that of Yorkrakine 7 is female nontransmissible.

Both complexes were present in the pollen of Yorkrakine 7 after 5 days of storage and no visible difference in homomer band intensities developed. As with 3-mile Rock 18, only 50 per cent of the viable Yorkrakine 7 pollen germinated in 10 per cent sucrose, and it exhibited homogenous growth rates in the styles of Gnarlbine 9. 
Embryo sac development in Yorkrakine 7 does not appear to differ from that described for alethal structural homozygotes by Beltran (1970). Without exception, the chalazal megaspore, in fertile ovules, gave rise to the embryo sac. In some ovaries, mature embryo sacs were observed in some ovules, and enlarged but degenerating megaspores in others; these were invariably in the chalazal position and remnants of the non-functional megaspores were still identifiable in the micropylar region. We assume that the undeveloped, enlarged chalazal megaspores are those containing the maternally non-transmissible complex. Since the micropylar megaspore failed to develop into the embryo sac in all 13 of the linear tetrads that could be observed, it is concluded that no Renner Effect (i.e., megaspore competition) is operative in Yorkrakine 7.

\section{Non recovery of one complex in crosses between two complex heterozygotes}

The Elachbutting dominant lethal effect. Graham 8 was determined as $1 / 3 \quad 1 / 1 \quad 1 / 32 / 21 / 1$ while Elachbutting 5 consists of the 11311 and 32121 complexes (see above). Forty four of the 51 adult progeny derived from crosses between these two complex heterozygotes were $1 / 1$ 1/1 $1 / 3$ 1/2 $1 / 1$ (table 1 , crosses 25 and 26 ). These results define the Graham 8 complexes as 11121 and 31321 and indicate a biased recovery of the Elachbutting 5 11311 and Graham 811121 complexes in this cross. The seven plants having other genotypes recovered from this cross can only be attributed to recombination. Both complexes are male and female transmissible in Elachbutting 5, see above, but the Elachbutting 532121 complex requires a suppressor of its dominant seedling lethal to be associated with it for survival beyond the seedling stage. Graham 8 presumably does not carry this suppressor, and so the Elachbutting 532121 complex was not recovered in the adult progeny of the crosses. On the other hand, the non-recovered Graham 831321 complex must have been associated with the Elachbutting 511311 complex in one or both crosses, but no $1 / 3 \quad 1 / 1 \quad 3 / 3 \quad 1 / 2 \quad 1 / 1$ genotype was recovered amongst the 51 progeny assayed; these complexes must share a common recessive lethal. Thus, divergence of the lethal systems in the Elachbutting and Graham Rock complex heterozygotes has resulted in the viability of only one of the four possible interpopulational complex combinations.

Redistribution of zygotic lethal system components between complexes. Merredin 9 has the genotype $1 / 31 / 21 / 32 / 31 / 1$ and is composed of the two complexes, 32121 and 11331 (table 1, cross 27). Mt. Stevens 3 has the genotype $3 / 3 \quad 1 / 2$ 1/3 $2 / 2$ $1 / 1$ and is composed of the two complexes 31321 and 32121 (table 1, cross 28). Significant nonrecovery of the Mt. Stevens 331321 complex was observed in the adult progeny of Merredin $9 \times M t$. Stevens 3 (table 1, cross 29). Both Merredin 9 complexes were equally recovered in cross 29 , but in 77 of the 87 progeny assayed, they were associated with the Mt. Stevens 332121 complex. The Mt. Stevens 331321 complex is fully transmissible in the pollen (table 1 , cross 28 ), so its reduced recovery in the progeny of cross 29 cannot be attributed to gametic lethality. The 10 per cent of progeny carrying the allozymic markers of the $M t$. Stevens 331321 complex may well be of recombinant origin; if not, the progeny containing this complex are rather unlikely to survive, even if they are not totally inviable. These results are explicable if we assume that the essentially non-recovered Mt. Stevens 331321 complex shares recessive lethals or debilitating genes in common with both of the Merredin 9 complexes while the Mt. Stevens 332121 complex shares lethals with neither. Thus, divergence of the lethal systems in Merredin and Mt. Stevens has resulted in the redistribution of lethals from one complex to both complexes in a second hybrid, and the loss of lethal homology between the other complex and both complexes in the second hybrid.

\section{DISCUSSION}

In contrast to earlier reports (James, 1965; Beltran and James, 1970) it is apparent that in Isotoma petraea complex hybrids, the complexes are not always transmitted with equal frequencies through both gametes. Where biased transmission occurs, it is due to gametic lethals which may operate in either or both sexes. Unequal recovery of equally transmitted complexes may also occur and may be due to dominant lethal factors expressed in juvenile seedling stages of plants which do not include a suppressor of that lethal in their genotype, and by the redistribution of components of the zygotic lethal system on one complex to both complexes in another complex heterozygote.

In a complex hybrid stabilised by a balanced zygotic lethal system, arrays of lethal factors are distributed throughout the complexes-there is evidence, for example, that there are three lethals in one complex and two lethals in the other in the Bencubbin $\mathrm{O}_{12}$ complex heterozygote (Beltran and James, 1970), and that the complex hybrids increase the efficiency of their balanced lethal sys- 
tems by accumulating earlier acting zygotic lethals (James, 1970). Whilst each inbreeding complex hybrid lineage must be composed of two complexes coadapted with respect to their lethal arrays, different lineages may harbour complexes which are not mutually coadapted. Thus, the two Elachbutting complexes are coadapted with respect to the late acting dominant lethal on one complex and its suppressing factor on the other. Gnarlbine structural homozygotes, however, which are alethal, do not carry this suppressor, and only one of the two possible Elachbutting $\times$ Gnarlbine twin hybrids is viable. Similarly, complexes which share a common lethal factor are not mutually coadapted, and when combined together, cannot survive. This type of non-coadaptation is reflected in the results of interpopulational crosses where, for example, one of the Mt. Stevens complexes is essentially non-recoverable in crosses with Merredin complex hybrids, while in reciprocal crosses between Elachbutting and Graham, only one of the four possible complex combinations was recovered.

Individual populations, then, must be composed of lineages which combine complexes which are mutually coadapted, at least with respect to their zygotic lethal systems, and also, presumably, for other factors which determine their relative fitnesses. If more than two complexes exist within a population, then all the viable pairs of complexes must be mutually coadapted, and an intrapopulational coadaptation must be generated and maintained. Different populations, which are essentially isolated because of the spatial effects associated with preference for the granite rock habitat exhibited by this species, would achieve their intrapopulational coadaptations independently of each other. In this process, the redistribution of the zygotic lethal system components has clearly generated complexes which are not mutually coadapted so that only a limited number of complex combinations can survive.

This type of divergence between populations would limit the facility with which interpopulational hybrid derivatives could be generated following a migrational event, and at its extreme, it could lead to reproductive isolation. Population systems of complex hybrids stabilised by balanced gametic lethal systems may not be subject to this type of divergence.

The balanced gametic lethal system is rare in Isotoma, having been found in only one amongst scores of plants investigated to date. While unbalanced gametic lethals are not particularly unusual, recessive zygotic lethality commonly provides the basis for permanent hybridity in these complex hybrids, either alone or in association with unbalanced gametic lethality. It is most likely that a balanced zygotic lethal system is the primitive mechanism of homozygote elimination in Isotoma, and that unbalanced then balanced gametic systems represent progressively derived conditions.

Since only functional heterozygotes can be produced by selfing in a complex hybrid stabilised by a balanced gametic lethal system, this system may well confer a selective advantage onto its carrier in terms of resource allocation at the post-pollination stages. However, the fecundity of such plants would be halved because of the random distribution of complexes to megaspores. Restoration of this fecundity could be achieved through an increase in ovule numbers. There is evidence that ovule numbers have increased in Isotoma complex hybrids (Ling, unpublished data). Restoration of fecundity could also be achieved through the development of a Renner Effect, as in Oenothera, or through a polarised distribution of the complexes such that the female transmissible complex was preferentially distributed to the functional megaspore, as is the case with the univalents in Leucopogon juniperinus (Smith-White, 1955). Although neither system is evident in Isotoma, strong positive selection pressure would be expected to operate on plants carrying female gametic lethals which displayed tendencies in either of these directions.

Isotoma petraea may be considered to be a young complex hybrid group (James, 1970), with its lethal systems still in the formative stages. Continuing evolution may well result in the replacement of its balanced zygotic lethal systems by balanced gametic lethal systems.

Isotoma is thus in contrast to Oenothera, where most of the complex heterozygotes are stabilized by gametic lethals. In Oenothera, male non-transmission of complexes is thought to have its origins in ancestral self-incompatibility (Steiner, 1956, 1957, 1960). In Isotoma, this cannot be the case; male non-transmission and female non-transmission have both arisen amongst populations of complex heterozygotes with zygotic lethal systems. By the same token, the balanced zygotic lethal system in Oenothera lamarkiana (Cleland, 1936) may be taken to be a remnant of the original complex hybrid genetic system in that genus, but it has been replaced, almost completely, by gametic systems in virtually all other Oenothera complex hybrid species. The male non-transmissibility described for 3-mile Rock 18, Yorkrakine 7, etc, and here referred to as (male) gametic lethality, 
involves a failure of otherwise normally appearing pollen grains to germinate. The phenomenon is very similar to self-incompatibility. It is possible that the male non-transmissibility in Oenothera complex hybrids has had its origin in a manner similar to that in Isotoma and not from any true self-incompatibility system in its ancestors. While true self-incompatibility is well known in Oenothera, e.g., Oe. organensis, (Emerson, 1939), its rarity amongst extant structural homozygotes closely related to the complex hybrid species (Stubbe and Raven, 1981) supports this view. Indeed, it would appear that self-incompatibility and complex hybridity may represent two alternative and mutually exclusive genetic systems in Oenothera. Both systems provide an answer to the challenge of inbreeding depression in small populations, by innovative outbreeding in self-incompatibility, and by conservation in complex hybridity.

We suggest that the evolution of complex hybridity in Isotoma and Oenothera has occurred along similar lines, and that the gametic lethal systems of Oenothera represent a derived condition, not associated with any ancestral self-incompatibility system. If this be so, then there is little evidence to support the theory proposed by Cleland $(1960,1972)$ that complex hybridity in Oenothera arose suddenly, as the consequence of hybridization between outbreeding lineages which differed with respect to their chromosome end sequences and which became stabilised by a subsequent adoption of autogamy. Rather, application of the evidence in Isotoma to the Oenothera situation strengthens the theory (Darlington, 1958) that complex hybridity arose in Oenothera as a response to inbreeding.

Acknowledgements We thank David Waldie, Edmund Dermer, Ling Pick Kiew and Stephen Carstairs for the help they provided in various ways, and the Australian Research Grant Scheme which supported some of the research reported here. We also record our appreciation of the meticulous perusual of the submitted draft by two anonymous referees whose efforts materially improved the paper.

\section{REFERENCES}

BELTRAN, I. C. 1970. Embryology of Isotoma petraea F. Muell. Aust. J. Bot., 18, 213-221.

BELTRAN, I. C. 1971. Ph.D. Thesis, University of Western Australia.

BELTRAN, I. C. AND JAMES, S. H. 1970. Complex hybridity in Isotoma petraea. III. Lethal system in $\mathrm{O}_{12}$ Bencubbin. Aust. J. Bot., 18, 223-232.
CLELAND, R. E. 1936. Some aspects of the cytogenetics of Oenothera. Bot. Rev., 2, 316-348.

CLELAND, R. E. 1960. A case history of evolution. Proc. Indiana Acad. Sci., 69, 51-64.

CLELAND, R. E. 1972. Oenothera, cytogenetics and evolution, Academic Press, New York, London.

DARLINGTON, C. D. 1958. The evolution of genetic systems, Oliver and Boyd, London.

EMERSON, S. 1939. A preliminary survey of the Oenothera organensis population. Genetics, 24, 524-537.

HOAR, C. S. 1931. Meiosis in Hypericum punctatum. Bot. Gaz., 92, 396-406.

JAMES, S. H. 1965. Complex hybridity in Isotoma petraea. I. The occurrence of interchange heterozygosity, autogamy and a balanced lethal system. Heredity, 20, 341-353.

JAMES, S. H. 1970. Complex hybridity in Isotoma petraea. II Components and operation of a possible evolutionary mechanism. Heredity, 25, 53-78.

JAMES, S. H., WYLIE, A. P., JOHNSON, M. S., CARSTAIRS, S. A. AND SIMPSON, G. A. 1983. Complex hybridity in Isotoma petraea. V. Allozyme variation and the pursuit of hybridity. Heredity, 51, 653-663.

KNOX, R. B. 1979. Pollen and allergy. Studies in Biology, 107, Edward Arnold.

MURTAGH, C. E. 1977. A unique cytogenetic system in Monotremes. Chromosoma, 65, 37-57.

O'BRIEN, T. P. AND MCCULLY, M. E. 1982 The study of plant structure. Principles and selected methods. Termacarphi, Melbourne.

OGAWA, K. 1954. Chromosome studies in Myriapoda VII. A chain association of the multiple sex-chromosomes found in Octocryptops sexspinosus (Say). Cytologia, 19, 265-272.

ROWELL, D. M. 1985. Complex sex-linked fusion heterozygosity in the Australian huntsman spider Delena cancerides (Aracnae: Sparassidea). Chromosoma, 93, 169-176.

SIMMONDS, N. W. 1945. Meiosis in tropical Rhoeo discolor. Nature, 155, 731.

SMITH-WHITE, S. 1955. The life history and genetic system of Leucopogon juniperinus. Heredity, 9, 79-91.

SNOW, R. R. 1963. Alcoholic hydrochloric acid carmine as a stain for chromosomes in squash preparations. Stain Technol., 38, 9-13.

STEINER, E. 1956. New aspects of the balanced lethal system in Oenothera. Genetics, 41, 487-500.

STEINER, E. 1957. Further evidence of an incompatibility allele system in the complex heterozygotes of Oenothera. Amer J. Bot., 44, 582-585.

STEINER, E. 1960. Incompatibility in the complex heterozygotes of Oenothera. Genetics, 46, 301-305.

STUBBE, W. AND RAVEN, P. H. 1981. Genetic self incompatibility in Oenothera subsect. Euoenothera. Science, 204, 327.

SYREN, R. M. AND LUYKX, P. 1977. Permanent segmental interchange complex in the termite Incisitermes schwarzi. Nature, 266, 167-168.

SYREN, R. M. AND LUYKX, P. 1981. Geographic variation of sex-linked translocation heterozygosity in the termite Kalotomes approximatus Snyder (Insecta: Isoptera). Chromosoma, 82, 65-88.

THEIN, L. B. 1969. Chromosome translocation in Gayophytum (Onagraceae). Evolution, 23, 456-465.

WEINS, D. AND BARLOW, B. A. 1975. Permanent translocation heterozygosity and sex determination in East African mistletoes. Science, 187, 1208-1209. 